\title{
Fabienne Kanor, Les chiens ne font pas des chats
}

\section{Stéphanie Celot}

\section{(2) OpenEdition}

\section{Journals}

\section{Édition électronique}

URL : http://journals.openedition.org/studifrancesi/8410

DOI : 10.4000/studifrancesi.8410

ISSN : 2427-5856

\section{Éditeur}

Rosenberg \& Sellier

\section{Édition imprimée}

Date de publication : 1 mai 2009

Pagination : 221

ISSN : 0039-2944

\section{Référence électronique}

Stéphanie Celot, «Fabienne Kanor, Les chiens ne font pas des chats », Studi Francesi [En ligne], 157 (LIII | I) | 2009, mis en ligne le 30 novembre 2015, consulté le 13 janvier 2021. URL : http://

journals.openedition.org/studifrancesi/8410 ; DOI : https://doi.org/10.4000/studifrancesi.8410

\section{Ce document a été généré automatiquement le 13 janvier 2021.}

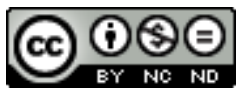

Studi Francesi è distribuita con Licenza Creative Commons Attribuzione - Non commerciale - Non opere derivate 4.0 Internazionale. 


\title{
Fabienne Kanor, Les chiens ne font pas des chats
}

\author{
Stéphanie Celot
}

\section{RÉFÉRENCE}

FABIENNE KANOR, Les chiens ne font pas des chats, Paris, Gallimard, 2008 («Continents

Noirs»), pp. 208.

1 Fabienne Kanor, qui avait débuté par des romans 'engagés' tels que D'eaux douces (2004) et Humus (2006), choisit pour son dernier texte narratif le genre apparemment désengagé du roman policier, dont elle adopte, de façon ironique, bon nombre de stéréotypes événementiels et langagiers. La narration alterne la drôle enquête du commissaire Jobin sur la mort de Roberto Salvares ( $Q$ Quelque chose cloche le lendemain des funérailles de Roberto Salvares», c'est l'incipit du roman) et l'existence de Salvio et d'Alicia, les enfants du défunt. Derrière cette façade amusante, le roman aborde deux problèmes très sérieux: celui du rapport entre père et fils et celui des rapports entre races, problèmes bien résumés dans le proverbe qui a été choisi comme titre du roman: Les chiens ne font pas des chats. Ce titre indique, bien sûr, les hérédités familiales, mais aussi les problèmes posés par les rapports entres des individus appartenant à des races différentes, dans un pays où le préjugé est encore très fort. Or, Alicia est blanche et riche, Roméo, son amant, est noir et pauvre: qu'est-ce qui peut naître de cette rencontre? Un amour fou, la fuite à Paris et, finalement, la séparation. Histoire banale et, en large mesure escomptée, mais ce n'est là que la charpente choisie par Fabienne Kanor pour faire revivre tout un monde riche en couleur, tragique et comique, avec des personnages inoubliables, comme le père de Roméo, Siméon, d'abord truand analphabète et plus tard sage autodidacte, qui élabore les quatre commandements «d'un jeune homme de bon sang», dont le dernier, qui récite «Tu n'oublieras pas les tiens» (p. 53), aura un rôle fondamental dans la décision de Roméo de quitter Alicia et de partir pour l'Afrique. 
2 Le plaisir du texte est dû à la richesse du langage et à l'ironie savante mise en place par l'écrivain, qui trouve son climax au moment où, après tant de recherches inutiles de la part du commissaire Jobin, c'est le chien du défunt qui découvre l'énigme de la mort de son maître: «Les chiens ne savent ni lire, ni compter, ni se rappeler la combinaison d'un coffre-fort [...]. Sauf que Cronenberg n'est pas un chien comme les autres [...] assis dans le fauteuil de son feu maître fait ce que personne n'a encore eu l'idée de faire jusqu'à présent: regarder d'un peu plus près dans le porte-document» (pp. 199-200). 